\title{
DESDE LA PRUEBA DOCUMENTAL EN ROMA A LA GRAFOTECNIA DEL SIGLO XXI: LA OBJETIVACIÓN DE LA PRUEBA DOCUMENTAL EN EL PROCESO JUDICIAL ESPAÑOL
}

\author{
Miriam Martín Paciente ${ }^{1}$
}

\section{Resumen}

El presente trabajo trata en un primer momento del estudio y distinción de los medios de prueba desde sus inicios en la época romana hasta la actualidad, su regulación en distintos países de la unión europea y los avances en implantación de los avances tecnológicos en algunos países

Se aportará novedades en el campo de la prueba documental no contempladas ni recogidas en nuestro ordenamiento. Como novedad, se propondrá en el mismo acto del juicio, y utilizando la tecnología, la verificación de las pruebas documentales, sobre todo incidiendo en aquellas en las que antes era de nuclear importancia la asistencia de perito caligráfico

Palabras clave: prueba documental, objetivación, derecho romano, evolución y proceso.

\section{Proemio}

Una de las características que describe el proceso civil español, es la detallada regulación de cada una de las partes del procedimiento. Estas pautas, vienen recogidas en la Ley de Enjuiciamiento civil 1/2000, de 7 de enero. En este texto legislativo, a partir del artículo 299, se pormenorizan los medios de pruebas que son admitidos en nuestro ordenamiento. En concreto, la prueba documental, es uno de los medios de prueba que más repercusión tiene en cualquiera de las jurisdicciones, incluso desde la época clásica. Ya desde el antiguo imperio romano, la prueba documental fue uno de los medios probatorios de mas transcendencia e importancia. En la ley vigente, se regula un medio de verificación de la prueba documental, por medio de un cotejo de letras, utilizando para esta labor a un perito.

La problemática se suscita, a partir de la verificación de las mismas, cuando hay que

\footnotetext{
${ }^{1}$ Graduado en Derecho en la ULPGC. Posgrado en Fiscalidad Internacional y Comunitaria USC, Máster de Acceso de la Abogacía en UNED. Colaboradora área de Derecho Romano, ULPGC. Espanha E-mail: miriam.martin111@alu.ulpgc.es
} 
hacer uso de un perito para dar un resultado que verifique su procedencia. La misma dinámica se produce, cuando lo que se pone en tela de juicio es la autenticidad de una firma o autógrafo que viniera aparejada al documento. En numerosas ocasiones, los peritos de partes, elaborarán dictámenes contradictorios sobre un mismo cuerpo de letras, creando en el juez un aura de incertidumbre sobre el contenido del mismo.

En la búsqueda por la legislación procesal de otros países, no se ha podido encontrar un sistema que facilite esta labor, encontrándonos con los mismos problemas que en España. En la última década, en este país, se han creado disposiciones reglamentarias que utilizan las nuevas tecnologías para su desarrollo, pero no en el ámbito procesal.

En el presente trabajo, en un intento de mejorar el sistema de verificación de la prueba documental, describiré un mecanismo que facilite esta labor. Mediante un sistema informático, que se podrá utilizar en las salas de los juzgados y tan solo con un dispositivo móvil, se verificará la prueba en el mismo acto del juicio, sin el requisito de la presencia del perito en la misma. Esto dará dinamismo a las causas, facilitando la labor del juzgador en la toma de decisiones.

En este estudio, partimos de un status quaestiones de los medios de prueba y la implementación a través de las TIC.

\section{La prueba documental en Roma}

Desde la antigua Roma hasta la actualidad, se han establecido reglas para dar fiabilidad y seguridad jurídica a los procedimientos judiciales. En una primera aproximación al proceso garantista y formalista en la época moderna, se hace palpable la transformación del concepto de veracidad y objetividad que ha caracterizado al elemento probatorio. El devenir de los siglos ha dejado patente los cambios en los antedichos conceptos, sufriendo una evolución en su esencia. Una de las primeras apariciones en el Ordenamiento Jurídco Romano de la prueba en el panorama judicial, se encuentra recogido en el Corpus Iuris Civiles, en los textos del Digesto 22, 3, 4 y 5, haciendo una diferenciación entre los testigos y la prueba documental. Durante algún tiempo, esas fueron las únicas fuentes probatorias existentes en la época clásica.

La primera nota significativa, la podemos encontrar en la inscriptio justineanea recogida en el Digesto 22.5.1 bajo las palabras "Aurelius Arcadius Charisius magister libellorum libro singulari de testibus", denotando la importancia de la prueba en los inicios de los acuerdos entre particulares, mucho antes de la llegada del derecho procesal. 
"Testimoniorum usus frequens ac necessarius est et ab his praecipue exigendus, quorum fides non vacillat."

Analizando el texto ${ }^{2}$, estaríamos ante una de las primera menciones del vocablo "prueba", que se utilizó entre particulares envueltos en alguna controversia. Este nuevo elemento, ayudaría a partir de ahora, a la resolución de los conflictos que acontecían a la ciudadanía en múltiples facetas de la sociedad romana.

En una primera mención a los testigos, queda patente que es la prueba estrella durante siglos, dándole un valor incalculable a ciertas declaraciones, basadas siempre en el criterio de los juzgadores. Para dar mayor verosimilitud a ciertos testimonios en dichos procesos, se establecían unas pautas sobre las características que debían contener, una vez llamados en audiencia pública, que era la forma más común de enjuiciamiento.

En relación a los Testium, en el Digesto 22.5.3 en su Modestinus libro octavo regularum nos meciona:

"Intestimoniis autem dignitas fides mores gravitas examinanda est: etideo testes, qui adversus fidem suae testationis vacillant, audiendinon sunt"’3.

Con estas palabras, se hace hincapié en la importancia de las características de los testimonios que se practicaban en el juicio, quedando en entredicho aquellas declaraciones que fueran titubeantes o poco fiables según el arbitrio de los enjuiciadores. Poco a poco, este valor superior que se le atribuye al testimonio de ciertas personas, ya sea por su posición en la sociedad romana o por sus profesiones, se fue diluyendo, dando paso a la prueba fundamental en la mayoría de los ordenamientos jurídicos modernos, como es la prueba documental. El testimonio, fundado en un documento escrito, pasaba a tener un valor superior, dando mayor credibilidad y firmeza a lo dicho, aunque con matices. En un primer momento, mantiene un gran valor el juramento ${ }^{4}$ hecho a viva voz, siendo este mejor valorado si se entraba en contradicción ante un texto manuscrito.

Es entonces, cuando se produce la diferencia entre documento público y documento privado. Para la valoración de los documentos públicos, no era necesario ningún tipo de testigo

${ }^{2}$ D.22,3,5.1 (Aurelius Arcadius Charisius magister libellorum libro singulari de testibus) Modesto, 8 Liber. ${ }^{3}$ D.22,3,5 (Modestinus, libro octavo regularum)

${ }^{4}$ Novela 73 de Justiniano, 3: "Si vero tale aliquid contigerit, quale in Armenia factum est, el aliud quidem faciebat collatio litterarum, aliud vero testimonia, tune nos quidem existimavimus ea, quae a viva dicuntur voce et cum iureinando, hac digniora fide, quam scriptum ipsam secundum se subsistere..." 
que corroborara el origen o autenticidad del mismo, teniendo valor probatorio pleno. Al contrario, si lo que se presentaba era un documento de origen privado, el particular que lo presentaba a audiencia, debía aportar como mínimo tres testigos que dieran fiabilidad y veracidad al documento.

Esta era la única manera, hasta el momento, de verificar los documentos, ya que no contaban con ningún adelanto tecnológico para esta labor. Esta verificación, ha alcanzado su punto álgido en estas últimas décadas, llegando a poder dar validez y objetividad a los documentos.

2.Concepto y descripción de los medios de prueba en proceso civil moderno

Los medios de prueba principales del derecho procesal civil son los recogidos en Ley 1/2000 de 7 de enero, Ley de Enjuiciamiento Civil $^{5}$ a partir del artículo 299, y se pueden enumerar de la siguiente manera:

El interrogatorio de las partes: Medio probatorio por el que cada parte puede solicitar al juzgador que la otra parte sea interrogada sobre hechos que puede conocer y guardan relación con la controversia. Asimismo, un colitigante puede interrogar a otro colitigante cuando exista discrepancia de intereses entre ambos. El interrogatorio de preguntas se formulará oralmente ${ }^{6}$ y siempre en sentido afirmativo. Antes de proceder a nuestro estudio, debemos tener en cuenta algunos conceptos que pasaré a describir de una manera somera:

- Documentos públicos: Son documentos públicos los otorgados por un funcionario público o depositario de la fe pública, dentro de los límites que dispone su cargo y de acuerdo con las formalidades prescriptas por la ley.

- Documentos privados: Son privados todos los documentos que sean presentados ante la causa por las partes $^{7}$ o de terceros, para intentar convencer al juez de sus pretensiones.

- Dictamen de peritos: El dictamen de peritos ${ }^{8}$ es uno de los medios de prueba reconocidos por la LEC conforme al cual, un sujeto ajeno al proceso aporta sus

\footnotetext{
${ }_{6}^{5}$ Ley 1/2000, de 7 de enero, de Enjuiciamiento Civil.Civitas.2009

${ }^{6}$ SERRA DOMÍNGUEZ, M., "La prueba documental", en "Instituciones del Nuevo Proceso Civil. Comentarios sistemáticos a la Ley 1/2000", Alonso-Cuevillas Sayrol, J., Barcelona, 2000, pág. 256

7 TEMPRANO VÁZQUEZ C, "El valor probatorio de los documentos privados y los motivos de impugnación”. Diario de la ley. Pág. 2, Edición Digital, 4 de septiembre de 2015.

${ }^{8}$ E. FONT SERRA, "El dictamen de peritos en la nueva Ley de Enjuiciamiento Civil", en Aportaciones del Profesor Eduardo Font a la doctrina jurídica, Madrid, 2004, pág.139.
} 
conocimientos científicos, técnicos, artísticos o prácticos con objeto de producir el convencimiento del juzgador acerca de las alegaciones. Suelen ser dictámenes complejos y basados en la técnica, esgrimidas por las partes.

- Reconocimiento judicial: El Tribunal, podrá, de forma personal y directa, realizar un examen de los hechos, personas, lugares o de las $\operatorname{cosas}^{9}$ que son objeto de prueba. Se diferencia de los demás medios de prueba en que, en este tipo de acto el juzgador personalmente es el que percibe la prueba y no a través de otras personas.

- Y el interrogatorio de testigos mediante prueba testifical en los procesos judiciales de cualquier jurisdicción.

También se reconocen como prueba los medios de reproducción de la palabra, el sonido y la imagen, así como los instrumentos que permiten archivar y conocer o reproducir datos, cifras y operaciones matemáticas ${ }^{10}$, este último grupo de pruebas es lo que se conoce como "nuevos medios de prueba", a los que les dedicaré el epígrafe siguiente. Incluso, si por cualquier otro medio no previsto en dicho artículo se consigue la certeza sobre hechos relevantes, también se admitirá como prueba por parte del Tribunal, adoptando las medidas que sean necesarias para ello.

Los medios de prueba están unidos al principio de legalidad que rige todo el funcionamiento procesal. Los únicos medios de prueba son los enumerados por la Ley de Enjuiciamiento Civil y todos ellos deben proponerse y practicarse ${ }^{11}$ según lo que establezca dicha Ley, por ello se dice que todos siguen el principio de legalidad.

En principio, todos los medios de prueba son admisibles en todos los procesos.

Lo importante en la actividad probatoria, es que se consiga llegar a un resultado por el cauce legal, obteniendo para esto, la verificación de pruebas que le den sentido a las pretensiones de las partes.

\section{Nuevos instrumentos probatorios}

Debido al devenir de la sociedad, junto a los medios de prueba ${ }^{12}$ clásicos, podemos

\footnotetext{
${ }^{9}$ ORDOÑO ARTÉS, C., “La prueba de reconocimiento judicial en el proceso civil español”, Madrid, 1987, pág. 171

10 ORMAZABAL SÁNCHEZ, G., "La prueba documental y los medios e instrumentos idóneos para reproducir imágenes o sonidos o archivar y conocer datos” Madrid, 2000, pág. 179

11 XAVIER ABEL LLUCH. "Valoración de los medios de prueba en el proceso civil". Madrid, 2006, pág. 311

${ }^{12}$ MONTERO AROCA, J. "La prueba en el proceso civil”, Thomson-Civitas, Navarra, 2007, pág. 226 vol.12,nº .04, Riode Janeiro,2019.pp.154-188 158
} 
enumerar un conjunto de medios probatorios que están basados en los avances técnicos que experimenta la sociedad. Respecto a la LEC 1/2000 regula, esencialmente, un doble instrumento probatorio: los soportes que permiten captar y reproducir sonidos e imágenes y los soportes que permitan archivar y conocer datos o cifras. Haciendo énfasis en este tipo de pruebas, procederé a enumerarlas en base al sistema que utilizan para captar la futura prueba en el proceso:

a) Instrumentos ${ }^{13}$ de captación y reproducción del sonido: se incluirían, en este primer grupo, todos aquellos elementos de captación y reproducción del sonido ${ }^{14}$ mediante registros mecánicos o magnéticos, sean autónomos o dependientes de aparatos de transmisión de cintas, etc.

b) Instrumentos de captación y reproducción de la imagen: son todos aquellos elementos de captación y reproducción. Esto se produce mediante registros físicos y químicos, como por ejemplo las fotografías, las diapositivas, las transparencias. En el campo de la medicina se podrían utilizar las resonancias magnéticas, las radiografías o los TAC (tomografías).

c) Instrumentos de captación y reproducción de la imagen ${ }^{15} \mathrm{y}$ del sonido: aquellos medios que de manera simultánea o sucesiva que registran de una manera física las imágenes y los sonidos, como son las videocámaras, videoclips o los DVD.

d) Instrumentos telemáticos: ejemplos de estos son los teléfonos, telégrafos, el fax o incluso el burofax. Incluimos en esta categoría a todos los registros que estos emitan.

e) Instrumentos informáticos: son los medios utilizados en el ámbito informático ${ }^{16}$, como son los CD Rom, los disquetes o los pen-drive.

f) Instrumentos para el control o la medición, tant

g) o físicos, químicos o físiológicos utilizados habitualmente en el ámbito médico $\mathrm{u}$ hospitalario. Estas mediciones suelen generar pruebas médicas ${ }^{17}$ que son los aceptadas por los tribunales.

Además de los medios mencionados, que vienen recogidos en la LEC, encontramos una

${ }^{13}$ GÓMEZ DEL CASTILLO Y GÓMEZ, M., M., “Aproximación a los medios de prueba en el proceso civil." Catedrático E.U. de Derecho Procesal. Universidad de Huelva, Derecho y conocimiento, vol. 1, págs. 77-90, ISSN 1578-8202

${ }^{14}$ ARMENTA DEU, T. “Lecciones de derecho procesal civil,” Marcial Pons, Madrid, 2013, pág. 171.

${ }^{15}$ PICO Y JUNOY, J. "El derecho constitucional a la prueba y su configuración en el nuevo proceso civil español"[ link: http://biblio.juridicas.unam.mx/libros/6/2554/31.pdf. ] [fecha de consulta: 4/ 04/2019]Pág. 548.

${ }^{16}$ HERNÁNDEZ GUERRERO / ÁLVAREZ DE LOS RÍOS, (1999) “Medios informáticos y proceso penal”, Estudios Jurídicos. Ministerio Fiscal, 1999-IV, p. 497.

17 DÍAZ REVORIO, F. J. (2008): "La constitución ante los avances científicos y tecnológicos: breves reflexiones al hilo de los recientes desarrollos en materia genética y en tecnologías de la información y la comunicación”, Revista de Derecho Político de la UNED, nº 71-72. 
referencia a estos medios de prueba en la Ley Orgánica 6/1985, de 1 de julio, del poder Judicial, en su artículo 230, se establece que "podrán utilizarse en el proceso cualesquiera medios técnicos de documentación y reproducción, siempre que ofrezcan las debidas garantías de autenticidad", añadiendo que "la ley regulará los requisitos y forma de su utilización" Basándonos en estas últimas palabras a las cuales hece referencia la ley, voy a proponer un medio de verificación de la prueba. En los casos en los que el documento no sea aceptado por alguna de las partes, por desconfiarse de su autenticidad o de su procedencia, tendremos un medio que nos ayude en esta tarea, al que llamaré el sistema "SmartPerit", que pasaré a describir a continuación.

3.1 Propuesta de sistema de objetivación de prueba documetal; "Sistema SMARTPERIT"

El elemento clave en la propuesta que quiero realizar se centra en la prueba. Definimos "prueba" como:

"Actuación procesal de parte, a través de los medios regulados en la norma procesal, por la que intenta acreditar los hechos que invoca como fundamento de su pretensión, con el propósito de acreditar al tribunal su certeza probatoria" 18

Como se indica en la ley ${ }^{19}$, se debe practicar en la vista pública, con publicidad y con inexcusable presencia judicial en el interrogatorio de las partes y de los testigos.

En lo referente a la prueba documental, la ley dispone, en cuanto a documentos originales, documentos públicos y documentos privados, que, cuando se quiera demostrar su autenticidad, se deberá realizar para la formación de un cuerpo de escritura para el cotejo de letras y la mera ratificación de la autoría del dictamen pericial. La problemática de la verificación de la prueba, viene reseñada muy adecuadamente por el profesor Ángel-Vicente Illescas Rus Magistrado ${ }^{20}$. Según el profesor, la doctrina científica, rechaza de una manera notoria, los dictámenes emanados de las salas al amparo de afirmaciones con el encabezado de "apreciación conjunta de pruebas practicadas", ya que la presunción de dichas afirmaciones, deja atrás la tan buscada seguridad jurídica. Partiendo este rechazo a la manera de valorar las reglas en su conjunto, podemos decir que la cuestión de "las reglas de valoración" recogidas en nuestro ordenamiento, no son sino una demostración de querer establecer unos parámetros para que el

\footnotetext{
${ }^{18}$ Real Academia Española. (2001). Diccionario de la lengua española (22. ${ }^{a}$ ed.). Madrid, España.

${ }^{19}$ Ley $1 / 2000$, de 7 de enero, de Enjuiciamiento Civil. art. 289

${ }^{20}$ ILLESCAS RUS, A. R., "Algunas cuestiones sobre arbitraje en la doctrina de las Audiencias Provinciales", Revista vasca de derecho procesal y arbitraje $=$ Zuzenbide prozesala ta arbitraia euskal aldizkaria, ISSN 02147246, Vol. 24, Nº. 2, 2012, págs. 263-338
} 
legislador no tome a libre discreción cualquier elemento probatorio que tenga en sus manos. Se establece en la ley, unos parámetros de valoración de la prueba, bajo la distinción, "sana critica" o valoración tasada. Esto hará que el incorrecto tratamiento de estas pruebas, provoquen causa de nulidad en el procedimiento, llegándose a poner a cero el entramado judicial, retrotrayendo al momento inicial para salvaguardarse las garantías que el proceso español nos ofrece.

Por lo tanto, voy a proceder a explicar de una manera pormenorizada, cual es el mecanismo por el cual podremos obtener esa objetivación de las pruebas realizadas, en concreto, las que pertenecen al grupo que se valoran en base a la opinio del juez. Como novedad, en el mismo acto del juicio se utilizará la tecnología, para validar un tipo de pruebas. En nuestra época, están al alcance de todos, los medios tecnológicos. Esto facilitará que los utilicemos como medio de verificación y objetivación de las pruebas documentales, sobre todo incidiendo en aquellos que antes era de nuclear importancia la asistencia de perito caligráfico. A mayor abundamiento, donde propongo la aplicación de las tecnologías de información y comunicación (TICS) al proceso, entendiendo por éstas a los sistemas de comunicaciones internas y externas, que utilizan ordenadores telemáticos. En un sentido, podemos decir, que "se denominan tecnologías de la información y las comunicaciones (TIC) al conjunto de tecnologías que permiten la adquisición, producción, almacenamiento, tratamiento, comunicación, registro y presentación de informaciones contenidas en señales de naturaleza acústica (sonidos) y óptica (imágenes)"

\subsection{Utilización de medios análogos en otros ámbitos}

Los avances tecnológicos nos permiten realizar tareas que hace unos años eran inimaginables. Los nuevos dispositivos electrónicos cada vez están más extendidos y son de uso cotidiano en la sociedad. Un claro ejemplo son los Smartphone o las tabletas, las cuales disponen de pantallas táctiles que permiten tener una nueva comunicación con las máquinas. Esto es una ventaja para la implantación de sistemas de adquisición de información manuscrita mediante estos dispositivos. Asimismo, existen claros ejemplos en su uso para diversas aplicaciones. Destaca la aplicación de esta tecnología cuando se va a emitir o renovar un DNI. La firma es adquirida mediante una pantalla táctil, y finalmente esa información es mostrada en el documento físico e incluida en el chip del DNI. Actualmente, la Policía Nacional ha alcanzado la cantidad de 60.867.575 DNI electrónicos expedidos ${ }^{21}$. Otro ejemplo se encuentra

${ }^{21}$ DNI electrónico. https://www.dnielectronico.es/PortalDNIe/ (visitada el 30 de enero de 2018) 
en las entidades bancarias, donde nos solicitan que firmemos sobre una tableta para digitalizar nuestra firma. O en las grandes superficies o comercios, donde con el uso de la tarjeta de crédito, si no tiene validación de PIN, nos solicitan que firmemos sobre una tableta.

Esta utilización de los dispositivos de pantalla táctil por organismos públicos y grandes empresas avalan su eficiencia y aplicabilidad, y, por tanto, puede ser llevado a otros ámbitos, como puede ser a las pruebas periciales y estudios forenses. Se plantea el poder adquirir la firma o un texto de forma indubitada, delante de un juez, y tras la aplicación de un sistema de verificación automático de firmas o de texto, mostrar la relación entre la muestra dubitada y la muestra indubitada.

\subsection{Procedimientos en el acto del juicio mediante el sistema Smartperit}

Para la utilización del sistema de verificación de firmas, como cuerpos de texto, debemos contar en un primer momento, con una serie de dispositivos móviles que serán los utilizados en la sala del juicio para su utilización. A este sistema lo llamaré "SmartPerit", nombre no utilizado en otro dispositivo o símil.

Deberemos contar por juzgado o sede judicial de una serie de iPad o Tablet provistas de este sistema que previamente han sido instalados en los dispositivos, donde cada uno de ellos cuente con una serie de números aparejados para su identificación. Si fuera necesario en otros procedimientos, se haría uso de esta numeración en segundas o terceras instancias.

Con autorización del juez, las partes podrán instar a la utilización de los dispositivos, los cuales estarán en custodia en sede judicial y será el personal encargado de auxilio judicial el que llevará a la sala que lo requiera. La utilización del sistema SmartPerit, se propondrá que se haga en propia sede judicial ${ }^{22}$, en presencia de todas las partes.

Una vez la Tablet en la sala, será el letrado de la administración de justicia el que verifique el funcionamiento de la misma, y a la que se le hará entrega de los escritos que son objeto de controversia para plantear sobre una muestra dubitada ${ }^{23}$, la muestra indubitada y así detectar si similitud. Los documentos donde se acredite su procedencia, y en la que no haya duda de su origen, (muestra indubitada), se almacenarán en el dispositivo, para posteriormente con la cámara de la Tablet recoger la muestra que queremos verificar (muestra dubitada) y así

\footnotetext{
22 TARUFFO, M ., "La prueba”, Marcial Pons, Madrid, 2008, p. 329

${ }^{23}$ Muestra dubitada. Es la muestra en la que existen dudas sobre su autenticidad. Por ejemplo, un documento con una firma que hay que valorar si es falsa o no. Por el contrario, la muestra indubitada. No existen dudas sobre su autenticidad. Pueden ser documentos aportados por el juzgado, cuerpos de escritura, documentos oficiales etc. Los documentos indubitados deben ser actuales en el tiempo, estar en buen estado, y ser suficientes.
} 
proceder a su comprobación por medio de técnicas caligráficas implementadas en el sistema "SmartPerit".

Una vez recogidos los resultados, estos deberán constar por escrito y quedar registrados tanto en el acta del juicio como en la sentencia emanada de la sala, junto al razonamiento del juez o magistrado para su valoración. Se presentará el resultado a ambas partes del procedimiento, dando opción a la disconformidad ${ }^{24}$ con el resultado de la misma, dejando constancia de este hecho. Seguirá siendo de valoración en base al criterio judicial las pruebas recogidas por el sistema SmartPerit.

Nos encontramos ante una herramienta que es capaz de objetivar las pruebas periciales en cualquier tipo de procedimiento, dejando a un lado los problemas que ocasionan aquellos dictámenes de peritos que distan mucho los resultados unos de otro.

Mediante un mecanismo sencillo, damos rapidez a una parte de procedimiento, la de la práctica de la prueba, proporcionándole a los jueces soluciones a problemáticas complejas, creando un mínimo coste en los juzgados mediante tecnología relativamente baja en coste, como puede ser las tabletas o ipads. Una vez finalizada la prueba, el juez o letrado de la administración de justicia entregará el dispositivo al auxiliar judicial, que será el encargado de custodiarlo y guardarlo donde se haya elegido para su almacenamiento. De una manera periódica, se deberá realizar una revisión y puesta a punto de las tabletas, para que estén es perfecto estado, aproximadamente cada 3 o 4 meses. Actualización de los sistemas operativos y calidad de la conectividad.

\subsection{La Grafotécnia, rama de las ciencias forenses}

La ciencia forense es la aplicación de prácticas científicas dentro del proceso legal, ya sean físicas, químicas, etc. Dentro de las diferentes ramas de las ciencias forenses se encuentra la pericial caligráfica, que es la rama en la que se basa el presente estudio. Pericia caligráfica, grafística, grafotécnia, grafoscopia ${ }^{25}$, grafología, grafocrítica y documentoscopia (entre otras), son las diferentes variantes que se encontrarán, dentro de la pericia caligráfica, para referirse al análisis de textos manuscritos dentro del proceso legal. Consistiendo básicamente,

${ }^{24}$ ARAGONESES MARTÍNEZ, S., HINOJOSA SEGOVIA, R. "Cien cuestiones controvertidas sobre la prueba en el proceso civil", Colex, Barcelona, 2000, p. 60

${ }^{25}$ FAUNDEZ-ZANUY, M., ELIOZONDO, D. A, FERRER-BALleSTER, M. A, y TRAVIESOGONZALÉZ, C. M, «Authentication of individuals using hand geometry biometrics: A neural network approach», Neural Processing Letters, 26 (2007), 201-16

[link: https://doi.org/10.1007/s11063-007-9052-y] [fecha de consulta: 10/03/2019] 
en un registro y descripción de rasgos y variables que deberán ser cotejadas entre el grafismo dubitado (grafismo cuestionado) y los grafismos indubitados (grafismos legítimos, atribuibles de manera cierta al sujeto). Es decir, se trata del conjunto de técnicas grafológicas cuyo objetivo es dilucidar la autenticidad o falsedad de cualquier documento ${ }^{26}$ manuscrito y la identificación de la autoría de los grafismos.

Nos encontramos ante una técnica avalada por innumerables publicaciones científicas, entre la que podemos destacar las que se realiza en la Universidad de las Palmas de Gran Canaria, donde se ha elaborado un sistema, el cual es capaz de detectar con una fiabilidad del 99,8 \% de acierto, en cuanto a la verificación de pruebas dubitadas en comparación con pruebas indubitadas. Estos resultados son los que avalan la utilización de estas técnicas en el campo judicial, ya que se garantiza la necesidad del esclarecimiento de los hechos con pruebas lo más objetivas posibles. Para la obtención de estos datos, se utilizan procedimientos utilizados por los peritos calígrafos para elaborar sus dictámenes, pero lo que realmente distingue a este mecanismo es la automatización de estos, facilitando su utilización por parte de personas que no tengan que tener una cualificación especialmente específica para su utilización, pudiéndose realizar por las personas designadas por el tribunal o por el propio juez.

Para entender un poco más, en que se basa la mecanización del proceso que ejecuta el perito en su análisis pasaré a enumerar alguno de los parámetros que son importantes para la identificación del individuo en cuanto a su escritura. La mayoría de estos parámetros a analizar son elementos estructurales de la escritura ${ }^{27}$ mencionando algunos como pueden ser:

a.La inclinación de las palabras (slant): Es el estudio que se elabora a partir de la inclinación de las letras de las palabras que las mismas formen, difiriendo cuando se tiene una inclinación de 90 grados $^{28}$, una mayor o una menor, siendo esta cualidad característica de cada persona en su escritura personal.

b. La velocidad de escritura: Se trata de identificar la cantidad de letras y palabras que el individuo es capaz de escribir en un lapso de tiempo determinado. A esto se le llama rapidez escritural en la que se busca la relación entre lo escrito y el tiempo. Dicha velocidad se puede clasificar como velocidad lenta, pausada y acelerada entre otras oscilando entre las 100 y 200

${ }^{26}$ GRAFOPEC, Pericia Caligráfica-Documentoscopia. Asociación nacional de expertos en Grafística y Documentoscopia, Delegación en Navarra. Actualización: 07/12/2010http://www.grafopec.com/servicios/pericia-caligrafica-documentoscopia/

${ }^{27}$ DUARTE, M. A. “Documentología II”, Licenciatura en Criminalística, Cátedra. Technical Rep. 2010 Pag. 34

${ }^{28}$ DE ANTÓN y BARBERÁ, F. Y MÉNDEZ BAQUERO, F., “Análisis de textos manuscritos, firmas y alteraciones documentales", Ed. Tirant lo blanch. 2005 
palabras por minuto.

c. Las regiones cerradas de algún tipo de letra en concreto $(a, o, e, d, \ldots)$, caracteriza la escritura de algún tipo de personas, que suele venir acompañada de una escritura más lenta de la media, estableciendo en las letras reseñada formas más circulares.

d. La longitud de las jambas. Son los trazos en los escritos ${ }^{29}$ en la zona superior e inferior de las palabras. Podríamos simplificarlo como el ancho de cada letra, o el cuerpo de la palabra, eliminando signos de puntuación y acentuando las prolongaciones ${ }^{30}$ de cada una de las letras. Estudiando el tamaño y las dimensiones de cada letra se puede apreciar dos tipos de elementos diferenciadores como son las escrituras extendidas, las escrituras concentradas.

Estas han sido una de las medidas utilizadas para establecer parámetros que nos permitan diferenciar una escritura de una persona de otra, la cual es distinta unas de otras como son las huellas dactilares. Estamos por tanto ante un proceso fiable, que garantiza a los usuarios de los mismos resultados utilizados en procedimientos donde hasta ahora quedaba al arbitrio de peritos de parte ${ }^{31}$ los resultados, distando muchas veces unos de otros en cuanto a resultados.

\subsection{Ventajas del sistema Smartperit}

Para validar este proceso, voy a hacer una breve descripción de las ventajas de la utilización de este sistema. Así, se destacan algunas características:

a)_Instantáneo. Este proceso electrónico realizado por la plataforma SmarPerit, se elabora a tiempo real, casi instantáneo, entre una horquilla de 3 a 5 segundos para la obtención de la verificación de la prueba manuscrita. Esto, dinamizará el proceso judicial, pudiéndose captar la prueba in situ en el acto del juicio. En la actualidad, los procesos muchas veces se ven ralentizados ante pruebas, en las que los dictámenes de los peritos encierran resultados contrarios unos de otros.

b) Fiable. Nos encontramos ante pruebas con una fiabilidad del $99 \%$ respecto a los resultados que nos ofrecen. Esto, nos da garantías de un proceso más objetivo y justo para

\footnotetext{
${ }^{29}$ SANTANA RAMIREZ, O. "Identificador Off-line de Escritura Manuscrita empleando Técnicas Periciales Caligráficas". Proyecto final de carrera, Universidad de Las Palmas de G.C. 2008.

${ }^{30}$ SANTANA O, TRAVIESO-GONZALEZ, C., M., FERRER M., A., ALONSO J.,

Writer identification based on graphology techniques. IEEE Aerosp Electron Syst Mag 25, 2010, pp. 35-42

${ }^{31}$ CORTÉS DOMÍNGUEZ, V., y MORENO CATENA, V. "Introducción al Derecho Procesal", Tirant lo Blanc, Valencia, 2015, p.15.
} 
ambas partes, ya que se contaría con la certeza del origen de la prueba documental en la causa. Este tipo de fiabilidad, es la misma que nos aporta la huella dactilar, en el proceso de identificación de personas. Es una de las notas más importantes de este tipo de procedimiento, ya que aporta la objetividad que validará la prueba. Este hecho, dará al proceso, unas garantías que no se podrían conseguir, solo con las valoraciones que se conseguirían con los dictámenes de los peritos caligráficos

c) Moderno. En la actualidad, es habitual que la comunicación entre los tribunales y los juzgados, sea por medios electrónicos mediante la firma digital y los recientes sistemas digitales instaurados (lexnet). Implementando en los juzgados y sedes judiciales con este sistema, estaremos un paso más cerca de la necesaria modernización del sistema procesal.

d) Económico. Para la obtención de la captación de la prueba, necesitaremos dispositivos móviles, como son las tabletas o Smartphone de entre 11 y 17 pulgadas. El coste en el mercado de este tipo de dispositivos ronda entre los 150 y 300 euros, tratándose de una gama media. Importante también sería la capacidad de autonomía de los dispositivos, teniendo una media de 3 horas aproximadamente.

e) Dinámico. Al tratarse de unos dispositivos móviles, se hace más sencillo la tarea de trasladar por la sala del juicio las tabletas, para la revisión de los propios jueces, secretarios judiciales o incluso por las propias partes si necesitaran consultar los resultados de las verificaciones. A la hora del almacenamiento de estos dispositivos

f) Íntegro. Importante es destacar que estas verificaciones son parte integrante del proceso, pudiendo mantener unos resultados permanentes y ordenados para futuros accesos, en posteriores recursos ${ }^{32}$ o consultas. El almacenamiento de los resultados de las verificaciones realizadas ocuparía un mínimo espacio en las sedes judiciales, gracias a los dispositivos de almacenamiento masivo que están comercializados en la actualidad

g) Finalista. La resolución que sea emanada por el sistema SmartPerit, podrán ser tratadas por el tribunal como veraces, dando por finalizados las controversias o desconfianzas que generan algún tipo de documentos. Esto dinamizará los procedimientos, y de una manera más ágil, finalizará con las dudas de la documental en el mismo acto del juicio.

Estudiando uno a uno las ventajas de este sistema, vemos que aporta grandes beneficios a la práctica de la prueba. Realizado un apoyo logístico a los juzgadores, creando una autonomía

32 ORTELLS RAMOS, M. "Formas del procedimiento y garantías fundamentales del proceso civil". Disponible en: http://www.scielo.cl/pdf/iusetp/v16n1/art13.pdf. [fecha de consulta: 10/04/2019] 
en las salas ante el incomparecimiento de los peritos, en el caso que ellos no pueden personarse en el procedimiento

\subsection{Desventajas del perito en la verificación de pruebas documentales}

La falta de información acerca de la preparación técnica real del perito calígrafo que subscribe el informe, su titulación, experiencia, etc, puede ser uno de los grandes problemas. Estos datos, situados al principio del documento, se presuponen cuando los expertos han accedido a la profesión con una base ${ }^{33}$ precaria, o bien, se trata de funcionarios cuyo mérito se limita a haber sido adscritos a un determinado laboratorio de la policía, sin estudios específicos previos. En ocasiones, esta situación, no es más que un modo de ocultar la verdadera formación o especialización del perito; al no existir colegios profesionales ${ }^{34}$ de peritos calígrafos, sino que trabajan accediendo de carreras muy dispares, ya que con frecuencia han cursado formación ${ }^{35}$ no reglada en academias o en posgrados a los que les han permitido acceder sin la exigencia de unos requisitos previos de cierto entidad.

Otro aspecto importante es insuficiencia de muestra para el cotejo de firmas/escritura o muestra inadecuada. Parece lógico que el perito que no cuente con elementos adecuados para realizar su trabajo haya de remitirse a las partes para que subsanen tal anomalía; de lo contrario, su trabajo puede verse destinado al fracaso. No es normal que no se cuente con material necesario para realizar la muestra, lo lógico es que se comunique con el juzgado para obtener cuanto necesite, en la medida de lo posible. También es frecuente el exceso de generalidades que no aportan precisión en la descripción, así como terminología inadecuada. El perito debe huir de limitarse a afirmaciones que no se refieran a datos concretos y significativos del caso, que ayuden al juzgador a entender sus conclusiones y llegar a un dictamen lo más fiable posible.

Otra cuestión destacable, es que la figura del perito, puede verse influenciada por las situaciones personales que no le dejan analizar de una manera objetiva las pruebas que tiene que cotejar. A diferencia de lo que se propone en este trabajo, el perito tiene sus condiciones cognitivas y volitivas condicionadas por su salud y situaciones personales, algo que no pasa con el sistema informático.

\footnotetext{
33 BALBUENA BALMACEDA, J., "Firmas auténticas y detección de firmas falsas". Editorial Textes \& Prétextes, Granada, 2003.Pág. 67

${ }^{34}$ CAPILla CASCO, A. y SÁNCHEZ-LOZANO VELASCO, J. en Patologías de la Audiencia Previa

(I). Economist \& Iuris $\mathrm{N}^{\mathrm{o}} 185$. Noviembre pag. 13

${ }^{35}$ SAP de Barcelona, sec. $9^{\text {a }}$, de 9 de marzo de 2016, Valoración razonada contenido peritaje.
} 
Y, por último, podemos pensar que en numerosas ocasiones no pueden dar conclusiones fiables. Si el perito ha realizado un trabajo exhaustivo, analizando todos los pormenores de los hallazgos del cotejo, está capacitado para ser claro en sus conclusions, aunque en ocasiones no suele ser determinante en sus aclaraciones.

\section{DIFERENTES MODELOS DE DERECHO COMPARADO}

En la actualidad, son muchos los países que se han hecho eco de la evolución en el campo tecnológico que se ha producido. Gracias a esto, la mayoría de los países han elaborado leyes que incorporan estos avances de manera paulatina. Después de un estudio por los principales exponentes de Europa y América, no hemos encontrado ningún tipo de mecanismo de verificación de pruebas documentales como se propone en el presente trabajo. Debido a esto, el siguiente capítulo, lo voy a dedicar, al estudio de una serie de países en el uso de las TIC's y los avances tecnológicos en los que se encuentran en proceso de incorporación en sus cuerpos legislativos.

\subsection{Alemania}

El Código procesal civil ${ }^{36}$ alemán es el llamado ZPO o Zivilprozessordnung ${ }^{37}$, en el se contiene la base de la actuación en el país germano. Aunque a lo largo del siglo XX, el país ha realizado una serie de reformas legislativas, la gran reforma que se le hizo al código el año 2000. Entre las finalidades del proyecto, se ve fundamental, que el proceso civil debe ser estructuralmente reformado para convertirlo en una herramienta, cercana al ciudadano, de modo que este pudiera acudir de forma eficiente y transparente. A ella, se sumaron la primera Ley de Modernización de la Justicia- Justizmodernisierunggesetz (JuMoG)-, del 2003/2004 y una disposición legislativa llamada Aplicación de Tecnología para la Comunicación en la Justicia- Justizkommunikationsgesetz (JkomG), del año 2005. Estas leyes modifican procesos en la primera instancia alemanes.

La ley alemana de 22 de marzo de 2005, sobre la modernización de las comunicaciones en materia jurisdiccional, ha hecho posible el tratamiento informatizado de los asuntos mediante el uso de un sistema de registro electrónico de los expedientes. También se permite dictar sentencia a través de fax por ordenador, con firma y sellos escaneados. La reforma introducida el 2005, refleja la regulación del empleo de medios de transferencia por sonidos e

\footnotetext{
${ }^{36}$ PÉREZ RAGONE, A., Y PALOMO VELEZ, D., “Oralidad y prueba: comparación y análisis crítico de las experiencias reformadoras del proceso civil en Alemania y España". Revista de Derecho de la Pontificia Universidad Católica de Valparaíso XXXII (Valparaíso, Chile, 1er Semestre de 2009), pp. 363-406.

${ }^{37}$ ROSENBERG, SCHWAB y GOTTWALD. 2011: “Zivilprozeßrecht”. München, 645.
} 
imágenes dentro del proceso, así como la posibilidad de que los actos procesales puedan ser simultáneamente transmitidos en sonido e imagen al lugar donde las partes o sus representantes se encuentran, aun cuando no sea físicamente en la sala o el tribunal. Dichas ventajas tecnológicas se reflejan en dos ámbitos:

Por un lado, en el ámbito intraprocedimental: Referido a los actos de comunicación entre los letrados y las partes, los escritos, en la que la protocolización de los actos procesales y las audiencias se facilitan por el empleo de las nuevas tecnologías como son las videoconferencias, los correos electrónicos y las tecnologías digitales. Este hecho se hace patente en los artículos 130, donde se regulan los documentos electrónicos judiciales, los que se producen entre los responsables judiciales, jueces, letrados de la administración de justicia, etc.

Por otro lado, el e-commerce. Este es el nombre al que se le atribuye las nuevas reglas del trafico electrónico y las normas en la valoración de los "documentos electrónicos o digitales" dentro del proceso. Este cambio en gran medida se debe a la entrada en vigor de la directiva de la Unión Europea sobre firma electrónica 1999/93/EG, el 13 de septiembre de 1999, donde Alemania tuvo que modificar su ley de firmas electrónicas, llamada Signaturgesetz del 1 de agosto de 1997.Además de estos cambios, la ley permite el escrito judicial digital que implica un medio que facilita y agiliza el acceso a la justicia. Al digitalizar no solo el inicio de las actuaciones procesales, sino además la actualización de los expedientes, las comunicaciones de los juzgados disminuyendo los tiempos y los costes. Por ultimo destacar, que la Ley de Comunicación en la Justicia ${ }^{38}$ incluye la fuerza probatoria de los documentos $^{39}$ digitales públicos y privados, si se llega a equipar o comparar con los documentos tradicionales no digitalizados.

Tras el análisis del progreso que ha hecho la legislación alemana en materia de nuevas ${ }^{40}$ tecnologías en sus procesos judiciales, se puede llegar a la conclusión, de que no existe ningún medio que se pueda equiparar al propuesto en el presente trabajo, aunque la digitalización documental esté presente en múltiples procedimientos del sistema judicial.

En Alemania, el art. 371 ZPO establece que los escritos electrónicos tienen la misma fuerza probatoria que los actos reflejados en documentos privados, y tendrán la fuerza probatoria del

\footnotetext{
${ }^{38}$ La Ley de Comunicación en la Justicia (Justizkommunikationsgesetz, JkomG, BGB1, 1, p. 837) 1 de abril del 2005, recoge las reformas que perfeccionan el régimen existente para el comercio electrónico en la justicia. ${ }^{39}$ En Alemania, el art. 371 ZPO establece que los escritos electrónicos tienen la misma fuerza probatoria que los actos reflejados en documentos privados, y tendrán la fuerza probatoria del acto auténtico

${ }^{40}$ LANGE, M., "Bezugnahme im Schriftsatz", NJW (Neue juristische Wochenschrift) 1989, p. 438
} 
acto auténtico.

\subsection{Francia}

La modernización del sistema procesal francés vas más despacio que en la mayoría de los países europeos de su entorno, pero haré referencia a los documentos electrónicos, que llevan aparejados cambios significativos a lo largo de estos últimos años.

Para referirnos al proceso civil en el país de Francia, debemos mencionar el Código Procesal Francés, del 2005, a partir de la Sección IV, recoge las pruebas que se pueden realizar en el procedimiento y la forma legal de practicarlas. La Ley 80/525, de 12 de julio de 1980, reforma el artículo 1348 del Código Civil francés, dándole al documento electrónico el mismo valor probatorio que al documento papel si cumple determinados requisitos que establece el código. Y, en la reforma de la Ley n. ${ }^{\circ}$ 2000-230, de 13 de marzo de 2000, sobre la adaptación al derecho de la prueba a las nuevas tecnologías de la informática, y relativa a la firma electrónica, dice en su art. 1316:

"La prueba literal, o prueba por escrito, resulta de un seguido de letras, caracteres, cifras o todo otro signo o símbolo dotados de significado inteligible, cualquiera que sea su soporte y sus modalidades de transmisión".

Esto indica, que el escrito con forma electrónica ${ }^{41}$ será admitido como prueba con igual fuerza que el escrito en papel.

En la Ley procesal francesa, el Código de Proceso Civil ${ }^{42}$ no se hace mención a una definición de documentos en el ámbito de la prueba, como sucede en la legislación española, pero si en su Código Civil. El otro aspecto en el que Francia ha dado un paso más a la modernización de su sistema judicial, es en lo referente a la firma. En el código procesal francés, se hace patente la importancia de la firma, electrónica en este caso, en el que establece, que existiendo un mecanismo fiable de identificación que garantice su vinculación con el acto del juicio, y confiando en la fiabilidad de dicho método, se consideren auténticas y fiables. A este respecto, se debe tener en cuenta lo recogido en el decreto ${ }^{43}$ del Conseil d'Etat, que admite prueba en contrario a estas verificaciones informáticas.

${ }^{41}$ DE PALADELLA SALORD, C., "El documento electrónico como prueba. La reforma del Código Civil Francés", Revista Electrónica de Derecho Informático, n. ${ }^{\circ} 26$, septiembre 2000, versión generada por vLex pág. 6.

${ }^{42}$ GASC, F. \& , P. "Reflexiones del código procesal civil francés". (2005).

${ }^{43}$ Orden 2005-674 de 16 de junio de 2005, Artículo 1 IV del Diario Oficial de 17 de junio 2005 
Por último, resaltar la forma tan minuciosa en que la legislación francesa regula los contratos electrónicos, donde lo que destaca, es la flexibilidad. En la ley se hace patente la laguna que existe en el ordenamiento jurídico en este tipo de operaciones, donde el soporte entre las partes del contrato, sea solo por medios informáticos, cabe la posibilidad del soporte papel en este tipo de procedimientos. Destacable es la falta de modernidad en el desenvolvimiento procesal y sus actuaciones. Salvo en casos excepcionales, como defensa de menores en casos penales o para archivar en filmografía histórica, no está permitido la grabación y difusión del acto del juicio en ningún tipo de medio. En el año 2017 se reforma la ley procesal francesa, donde se aceptan las videoconferencias para las declaraciones que sean necesarias, pero la prohibición de grabación sonora o audiovisual, algo ya instaurado en la Ley de enjuiciamiento civil española, facilitando en los posteriores recursos su revisión.

\subsection{Reino Unido}

Para la regulación del proceso civil inglés, debemos acudir a su ley que está en vigor desde el año 1999, Civil Procedure Rules, llamado por las siglas CPR, que pormenoriza los medios de pruebas existentes, dejando a los jueces su interpretación y aplicación en la mayoría de los casos. A partir del artículo 31 del código procesal en adelante, se detalla el papel de cada una de las partes, así como el tratamiento que tienen que tener las fotografías, planos o documento en soporte digital llamado en el CPR, "Use of plans, photographs and models as evidence". No se recoge una lista cerrada de posibles pruebas y formatos, y se aplicará un criterio abierto, para que el juez tenga libre disposición de aceptarlas si cree que su morfología y contenido.

En el ámbito penal, los cambios han sido regulados de una manera más activa, dado la importancia de las actuaciones de las investigaciones policiales. En Reino Unido prevén expresamente la posibilidad de utilizar dispositivos electrónicos para lograr la captación y grabación de las conversaciones privadas que el sospechoso mantenga en dichos lugares. Igualmente, debería señalarse expresamente que tales dispositivos podrían perseguir la obtención tanto de sonidos como de imágenes, y que podrían ser colocados tanto en el exterior como en el interior del domicilio o lugar cerrado, o bien ser portados por el agente infiltrado, siempre con el correspondiente control judicial, dada la injerencia que tales medidas pueden ocasionar en los derechos de los sujetos investigados. El Reino Unido también adaptó su legislación en el año 2000 a través de la Regulation of Investigatory Powers Act (RIPA).

Importante destacar, un sistema pionero en el panorama europeo, denominado la "democracia online", la cual es reflejo del esfuerzo del gobierno inglés, la incorporación de los 
medios telemáticos y avances tecnológicos en todos los aspectos que afecten a la ciudadanía.

Se trata de un sistema inspirado en los Speaker's Corner ${ }^{44}$ que ha dado lugar a la creación de foros de debate de distinto calado político. El mejor ejemplo es UKCOD ("U.K. Citizens' Online Democracy") ${ }^{45}$ que fue creado por Irving Rappaport y se define como una organización no lucrativa, cuyo ámbito de desarrollo es un espacio. electrónico autónomo estructurado sobre la base de una plataforma de e-mails y web site cuyo objetivo fundamental es "to promote the non-partisan advancement of polital education for the general public" ${ }^{\text {"46 }}$, o dicho de otro modo, que la ciudadanía entienda y conozca la políticas que se están instaurando en el país.

Entre los objetivos propuestos para la utilización de este sistema destacaban:

a)- Conseguir un mayor grado de consultas interactivas entre los representantes políticos y sus electores. No existen dudas sobre los sistemas de representación instaurados, únicamente se pretende llevar a cabo un incremento en lo referente a la utilización de instrumentos tecnológicos para generar una mayor cercanía del ciudadano.

b)- Facilitar la comunicación entre políticos y ciudadanos, más que motivar a los ciudadanos para que establezcan lazos de unión entre sí.

c)- Establecer una democracia online, elemento útil para aquellos que pretendan acceder a información de carácter "sensible".

d)- Promover la utilización de un software denominado "Preferendum", que sirva como procedimiento para realizar actividades de votación, estructurado e interactivo. Se trata de llevar a cabo el establecimiento de agendas de discusión que detecten modelos de opinión a efectos de conformar y obtener un consenso sobre las materias de discusión que pueda servir de referencia a los agentes políticos.

e)- Determinar cómo va a contribuirse en la esfera política pública; El proyecto en sí mismo, es considerado una oportunidad para extender la participación democrática, más que la simple oferta de un nuevo canal de comunicación para los mismos ciudadanos.

\footnotetext{
${ }^{44}$ Speakers' Corner, se puede traducir como "el rincón del orador" y consiste en una zona donde se permite hablar en público. Se les permite hablar a los oradores siempre que las autoridades no consideren que sus palabras contradigan alguna ley.

${ }^{45}$ GALlaGHER, T.:" UK Citizens ` Online Democracy: A case Study", University of Oxford, 1997 www.aikens.org

${ }^{46}$ La traducción literal es: "promover el avance no partidista de la educación política para el público en general". 
5.Nuestra propuesta de "Lege ferenda"

Modelo de LEC, Ley 1/2000, de 7 de enero y modificación legislativa

Sin duda el perito, debe desarrollar un dictamen sólido y razonado, tanto en su presentación, como en su metodología y desarrollo analítico. El perito ${ }^{47}$ debe saber que su actuación en el juicio resultará la mayor parte de veces fundamental para la consideración de la prueba, teniendo en cuenta que es de valoración libre. Esto se hace más evidente, en los casos de contradicción pericial, donde concurrirán dictámenes contradictorios en un mismo proceso, situación que se da con mucha frecuencia en cuanto que la ley procesal establece la aportación de dictámenes en la fase de alegaciones por parte de actores y demandados.Al perito, no sólo se le exigirá una buena expresión escrita en su informe, formulando sus razonamientos con claridad y rigor, sino que deberá confirmar estas conclusiones en el acto de juicio oral, donde el escenario en el que se encontrará es completamente distinto. Aquí deberá declarar con precisión y en la sala de vistas. Sin duda entran en acción otras cualidades del Perito como son la autoconfianza, autocontrol, capacidad de síntesis, pero también de improvisación, agilidad mental y buena oratoria. No me cabe duda que un buen dictamen puede verse diluido o incluso perder credibilidad con una actuación deficiente del perito en el acto de juicio oral, siendo este momento procesal el que sin duda merece mayor atención. Así pues, con la LEC del 2000 resulta más exigente la capacitación del perito en el proceso, pues a su conocimiento técnico y científico se deberá unir su capacidad narrativa tanto en el ámbito escrito como en el verbal. En este sentido, el sistema planteado en el presente estudio, deja a un lado cuestiones de oratoria que tengan como centro al perito. Deja a un lado que el perito deba preparar, estructurar y revisar concienzudamente el dictamen que aporta al proceso, ya que éste será objeto de un pormenorizado análisis y «dirección» por las partes, para luego someter al perito a un análisis durante su exposición verbal. Cualquier error o contradicción que pueda detectarse en el informe escrito podrá servir como arma para desmontar las declaraciones de los peritos, pues a veces se pueden escapar fallos u omisiones a pesar de haber repasado el texto en repetidas ocasiones.

Por otro lado, resulta muy importante que exista una estrecha colaboración entre el letrado y el perito de carácter privado que ha emitido el dictamen a su instancia, con el fin de que éste, desde su vertiente técnica, le asesore sobre el tipo de preguntas que deberá formularle. En caso de que exista un dictamen contradictorio, el perito deberá analizarlo con la debida

${ }^{47}$ GONZÁLEZ PILLADO, Esther, "La prueba pericial en la nueva Ley de Enjuiciamiento Civil", Revista Xurídica Galega, n 27, 2000, pp. 307-344. 
profundidad para señalar a su letrado aquellos puntos sobre los que difiere, así como cualquier error, contradicción o punto débil, y ayudarle de este modo a preparar el interrogatorio de este Perito contrario en cuanto al contenido, orden y alcance de las preguntas. La falta de preparación y contundencia en el interrogatorio pericial, sin haber incidido en puntos esenciales del propio dictamen de su perito y en los puntos oscuros o erróneos del dictamen contrario, pueden minimizar o anular el alcance y valor de su prueba.

Con el fin de mejorar el sistema de valoración de la prueba en este procedimiento innovador en nuestra ley de procedimiento civil, en primer lugar, mencionare los artículos de la misma que serán objeto de modificación ${ }^{48}$. Dichos artículos se recogerán casi en su totalidad en la Sección Quinta bajo el encabezado “Del dictamen de peritos”. Este será un procedimiento que complementaran sus dictámenes de una manera fácil, dinámica y que puede realizarse con un dispositivo móvil.

La primera introducción debe realizarse en el artículo 299, en la que debe quedar reflejada el sistema propuesto como un medio de prueba, para que posteriormente se pueda regular las actuaciones en el acto del juicio.

Artículo 299. Medios de prueba.

1. Los medios de prueba de que se podrá hacer uso en juicio son:

1. ${ }^{\circ}$ Interrogatorio de las partes.

2. ${ }^{\circ}$ Documentos públicos.

3. ${ }^{\circ}$ Documentos privados.

4. ${ }^{\circ}$ Dictamen de peritos.

Artículo introducido:

5. ${ }^{o}$ Verificación sistema "SmartPerit"

6. ${ }^{\circ}$ Reconocimiento judicial.

7. ${ }^{\circ}$ Interrogatorio de testigos.

La siguiente referencia en la ley, se debe realizar en la valoración que tienen los dictámenes periciales en este tipo de procedimientos, ya que la aportación de este sistema,

${ }^{48} \mathrm{M}^{\mathrm{a}} \mathrm{L}$. ESCALADA LÓPEZ, "El dictamen de peritos en la LEC: Aspectos generales. Especial atención a su naturaleza jurídica", en Revista de Derecho Procesal, 2007, p. 311. 
puede llevar aparejado el cambio en la ley, y poder considera la prueba como tasada, basada en la fiabilidad del sistema

Artículo 348. Valoración del dictamen pericial.

1.El tribunal valorará los dictámenes periciales según las reglas de la sana crítica

A nuestro juicio, se podría incluir los siguientes apartados que se resaltan en negrita cursiva a continuación;

2.El juez podrá admitir aquellos dictámenes que sean emitidos por dispositivos electrónicos en la misma sala de la vista mediante la plataforma "SmartPerit".

Artículo 349. Cotejo de letras.

1.Se practicará por perito el cotejo de letras cuando la autenticidad de un documento privado se niegue o se ponga en duda por la parte a quien perjudique.

2.En el caso de que sea requerido por el alguna de las partes o por el propio tribunal, se practicará en la sala el cotejo de las palabras, firmas o cuerpo de letras que sea requerido por el procedimiento de "SMARTPERIT"

3.También podrá practicarse cotejo de letras cuando se niegue o discuta la autenticidad de cualquier documento público que carezca de matriz y de copias fehacientes según lo dispuesto en el artículo 1221 del Código Civil, siempre que dicho documento no pueda ser reconocido por el funcionario que lo hubiese expedido o por quien aparezca como fedatario interviniente.

4.El cotejo de letras se practicará por perito designado por el tribunal conforme a lo dispuesto en los artículos 341 y 342 de esta Ley.

3. En caso de ser posible sustituir a los peritos por el procedimiento "SmartPerit", deberán todas las partes estar de acuerdo, con previa autorización del juezo magistrados del procedimiento.

Artículo 350. Documentos indubitados o cuerpo de escritura para el cotejo.

1.La parte que solicite el cotejo de letras designará el documento o documentos indubitados con que deba hacerse.

2.Se considerarán documentos indubitados a los efectos de cotejar las letras: 
$1{ }^{\circ}$ Los documentos que reconozcan como tales todas las partes a las que pueda afectar esta prueba pericial.

2. ${ }^{\circ}$ Las escrituras públicas y los que consten en los archivos públicos relativos al Documento Nacional de Identidad.

3. ${ }^{\circ}$ Los documentos privados cuya letra o firma haya sido reconocida en juicio por aquel a quien se atribuya la dudosa.

4. ${ }^{\circ}$ El escrito impugnado, en la parte en que reconozca la letra como suya aquel a quien perjudique.

3.A falta de los documentos enumerados en el apartado anterior, la parte a la que se atribuya el documento impugnado o la firma que lo autorice podrá ser requerida, a instancia de la contraria, para que forme un cuerpo de escritura que le dictará el tribunal o el Secretario Judicial.

Si el requerido se negase, el documento impugnado se considerará reconocido.

4.Si no hubiese documentos indubitados y fuese imposible el cotejo con un cuerpo de escritura por fallecimiento o ausencia de quien debiera formarlo, el tribunal apreciará el valor del documento impugnado conforme a las reglas de la sana crítica.

Artículo 351. Producción y valoración del dictamen sobre el cotejo de letras.

1.El perito que lleve a cabo el cotejo de letras consignará por escrito las operaciones de comprobación y sus resultados.

2.Será de aplicación al dictamen pericial de cotejo de letras lo dispuesto en los artículos 346, 347 y 348 de esta Ley.

Artículo 352. Otros dictámenes periciales instrumentales de pruebas distintas.

Cuando sea necesario o conveniente para conocer el contenido o sentido de una prueba o para proceder a su más acertada valoración, podrán las partes aportar o proponer dictámenes periciales sobre otros medios de prueba admitidos por el tribunal al amparo de lo previsto en los apartados 2 y 3 del artículo 299.

Parte nuclear de esta propuesta de cambio de regulación, es el procedimiento en el acto del juicio. Dicha actuación tiene que estar explicada de una manera exhaustiva, ya que se deben respetar los cauces formales y procedimentales para que sea considerada prueba válida. Debe quedar constancia del uso de este sistema, dejando constancia por el letrado de la 
administración de justicia para su control interno por medio del juzgado.

Y por último, se plantea desde un punto de vista de lege ferenda la siguiente legislación:

Artículo 352: Procedimiento de la prueba por el sistema "SmartPerit"

1.Se utilizarán los dispositivos que se tengan al efecto en la sala correspondiente, pudiendo ser dispositivos con número de serie registrados en sede judicial

2.El responsable de la custodia de los dispositivos los entregará al auxiliar judicial de sala para que sea utilizada por el Letrado de la administración de justicia o quien designe para tal fin.

3.Proceder a la verificación de los documentos en la propia sala, a la vista de todas las partes, bajo la vigilancia y como fedatario el propio juez y el Letrado de la administración judicial.

4.Recogidas la muestras mediante la verificación con el dispositivo móvil, se procederá al análisis de los resultados obtenidos de las partes y del propio juez

5.La prueba documental verificada en su origen por el sistema "SmartPerit" tendrá la valoración en base a la sana critica del juez o magistrados.

6.En caso de inconformidad con el resultado de la prueba obtenida con el sistema "SmartPerit", se podrá realizar el protesto para futuras revisiones de los resultados de la misma.

Este articulado podría aspirar a ser lo recogido para el procedimiento para la verificación de documentos "SmartPerit", el cual, lejos de excluir a los peritos en el procedimiento $^{49}$, complementa su actuación dándole validez a sus dictámenes y reforzándolos.

6. Legislación complementaria a la ley de Enjuiciamiento Civil 1/2000, de 7 de enero

Respecto a la integración de las nuevas tecnologías en nuestro sistema judicial podemos mencionar una serie de disposiciones legislativas relativas, que reseñan los cambios

\footnotetext{
${ }^{49}$ POZO MOREIRA, F. J., "La presentación de demandas y documentos y la realización y notificaciones en los Juzgados y Tribunales del Orden social por medios telemáticos: la reforma del Procedimiento civil y Laboral por la Ley 41/2007’, Diario La Ley, núm. 6890, 2008, p.45.
} 
en la sociedad en cuanto a los usos de dispositivos móviles cada vez más comunes. A continuación, mencionaré las leyes más relevantes en nuestro ordenamiento jurídico, que hacen viable el cambio legislativo propuesto. El poder legislativo, lleva años haciendo un esfuerzo por la implantación de mecanismos, que facilitan las actuaciones judiciales a los ciudadanos y su acceso a estas instituciones.

\subsection{Sistema Lexnet}

Una de las implantaciones más relevantes en el panorama nacional en el uso de las nuevas tecnologías para los procesos judiciales es el sistema Lexnet ${ }^{50}$.

El RD 84/2007, de 2 de enero, que fue publicado en el BOE n⿳038, de 13 de febrero de 2007, en el que se regula la introducción en la administración de justicia del sistema informático Lexnet. Consiste en la presentación de escritos y documentos, juntos con sus copias mediante la realización de una plataforma informática habilitada para la recepción de los órganos judiciales.

El sistema Lexnet, está dentro del Plan de modernización de la Administración de justicia, en la que incentiva a la administración al uso de las nuevas tecnologías en los sistemas de gestión procesal. Para esta tarea, se utiliza un sistema de correo electrónico securizado ${ }^{51}$ que proporciona el verbo securizar, formado a partir de voces inglesas como to secure o security, se encuentra ya en el diccionario español, con el significado concreto de 'hacer que un cristal sea de seguridad' («vidrio segurizado»), lo que hace posible ampliar este significado para aplicarlo a una tarjeta de crédito, al pago realizado con ella, a un ordenador o a un entorno informático de mayor seguridad en la comunicación mediante la firma electronica instaurada por medio de la Casa de la Moneda y Timbre (FNMT).

El sistema Lexnet es obligatorio ${ }^{52}$ para los entes que el Real Decreto describe, inscripción y registro en el sistema como son:

-Letrados de la Administración de justicia

\footnotetext{
${ }^{50}$ CREMADES GARCÍA, V. - ALACID BAÑO, L. M., "Lexnet: el reto de las Nuevas Tecnologías en la administración de justicia", Revista de la Facultad de Ciencias Sociales y Jurídicas de la Universidad Miguel Hernández, núm. 2, 2007, pp. 46-49

${ }^{51}$ El verbo securizar, formado a partir de voces inglesas como to secure o security, se encuentra ya en el diccionario español, con el significado concreto de 'hacer que un cristal sea de seguridad' («vidrio segurizado»), lo que hace posible ampliar este significado para aplicarlo a una tarjeta de crédito, al pago realizado con ella, a un ordenador o a un entorno informático.

${ }^{52}$ MAGRO SERVET, Vicente, "La comunicación entre Abogados y Procuradores con los órganos judiciales por medios de las nuevas tecnologías de la información y la comunicación”, Diario La Ley Núm. 5966, 2004, p. 1514.
} 
-Gestión, Tramitación y Auxilio judicial

-Abogacía del Estado

-Ministerio Fiscal

-Procuradores y Abogados en ejercicio

-Graduados sociales

-Órganos de la Administración General del estado y sus organismos públicos

La mayor ventaja que ofrece este sistema de recepción de documentos telemáticos, es que se encuentra activo las 24 horas del día, los 365 días del año, estableciendo los plazos de una manera claro, utilizando para esta tara el temporizador que lleva aparejado el sistema.

6.2 Ley 59/2003, de 19 de diciembre de firma electrónica

La elaboración de esta ley ${ }^{53}$, se debe a la transposición de la Directiva 1999/93/CE, del Parlamento europeo y del Consejo, de 13 de diciembre de 1999, por la que se establece un marco para la firma electrónica, para contribuir a su uso ${ }^{54}$ y al reconocimiento de la misma en la Unión Europea. Se crea así, un marco jurídico para la firma y determinados servicios de certificación a nivel internacional, garantizando así su correcto funcionamiento.

La presente ley regula la firma electrónica ${ }^{55}$, la cual podemos definir como el conjunto de datos en formato electrónico que se utilizan para identificar a la persona por medios telemáticos. Lo que garantiza que los órganos judiciales y demás entes públicos crean en la eficacia de este sistema, viene dado por las cuatro características de la firma electrónica, que son:

a. Identidad, generando en el organismo que recibe la firma, la certeza de la identidad de la persona que la está proporcionando.

b. Integridad, ya que será un conjunto de caracteres personales que formaran parte de un todo, sin posible fraccionamiento

c. Confidencialidad, por el uso exclusivo del propietario de la firma

d. El no rechazo de la firma

\footnotetext{
${ }^{53}$ MARTÍNEZ NADAL, A., La ley de firma electrónica, Civitas, Madrid, 2000, p.12

${ }^{54}$ LLANEZA GONZÁLEZ, P., "La firma electrónica”, en Iuris-actualidad y prácticas del Derecho, no 38, abril 2000, p. 47

${ }^{55}$ HUGUET TOUS, P. L., "Pistoletazo de salida para la presentación telemática de escritos en los órganos judiciales: el Consejo de Ministros aprueba el Real Decreto que regula la utilización del Sistema LEXNET", La Ley: Revista jurídica española de doctrina, jurisprudencia y bibliografía, núm. 4, 2007, pp. 1446-1448
} 
En la presente ley se establece, a efectos judiciales, que se puede comparar el documento en soporte papel y en soporte electrónico ${ }^{56}$ al mencionar en su artículo 3:

"el soporte en que se hallen los datos firmados electrónicamente será admisible como prueba documental en juicio".

Por lo tanto, podemos llegar a la conclusión, que si la prueba aportada en documento electrónico no es impugnada por ninguna de las partes o por el propio juez será considerará como prueba tasada.

6.3 Ley 34/2002, de 11 de julio, de servicios de la sociedad de la información y de comercio electrónico

La ley sobre Servicios de la Sociedad de la Información y de Comercio Electrónico en España LSSICE (Ley 34/2002, de 11 de julio). Desde que entró en vigor en octubre de 2003, los responsables de sitios web de comercio electrónico deben cumplir con una serie de requerimientos específicos.

Esta ley obliga a las empresas "prestadores de los Servicios de la Sociedad de la Información". Por prestador de servicios se entiende a todos aquellos, tanto empresas como particulares, que realizan algún servicio por Internet a petición del usuario, incluidos los servicios no remunerados pero que supongan carácter económico para la empresa o particular que los ejerce. Por ejemplo, son prestadores de servicios las empresas que disponen de una web con un catálogo de productos, aunque no vendan por Internet.

En la presente ley se compara la validez de un contrato en soporte papel y otro en soporte electrónico a través de Internet y menciona en su artículo 24:

Art. 24. Prueba de los contratos celebrados por vía electrónica.

1. "La prueba de la celebración de un contrato por vía electrónica y la de las obligaciones que tienen su origen en él se sujetará a las reglas generales del ordenamiento jurídico".

6.4 Ley 56/2007, de 28 de diciembre, de medidas de impulso a la sociedad de la información

\footnotetext{
${ }^{56}$ MARTÍNEZ NADAL, A., "Comentarios sobre la regulación de la firma electrónica", en Partida Doble n ${ }^{\circ}$ 106, diciembre 1999, p. 19.
} 
que equipara la factura tradicional y la factura electrónica.

En la Ley 56/2007 de 28 de diciembre de Medidas de Impulso de la Sociedad de la Información se introducen una serie de innovaciones en materia de facturación electrónica y de refuerzo de los derechos de los usuarios y se hacen las modificaciones necesarias en el ordenamiento jurídico para promover el impulso de la sociedad de la información.

Reseñable es lo dispuesto en su artículo 1 en cuanto a la utilización ${ }^{57}$ de medios electrónicos para proceder a verificar información:

Art. 1. Medidas de impulso de la factura electrónica y del uso de medios electrónicos en otras fases de los procesos de contratación.1. La facturación electrónica en el marco de la contratación del sector público estatal será obligatoria en los términos que se establezcan en la Ley reguladora de la contratación en el sector público y en su normativa de desarrollo. A estos efectos, se entenderá que la factura electrónica es un documento electrónico que cumple con los requisitos legal y reglamentariamente exigibles a las facturas y que, además, garantiza la autenticidad de su origen y la integridad de su contenido, lo que impide el repudio de la factura por el emisor.

En la actualidad, no se duda del origen y validez de las facturas electrónicas, ya no solo en su formato papel, sino en cualquier medio electrónico que sea emitido por una fuente valida, establecimiento comercial o estamento público. Este hecho, da a un más si cabe, validez a procesos tecnológicos en otros ámbitos más allá del comercial.

\section{Conclusiones}

En base a lo antes señalado podemos realizar las siguientes reflexiones finales:

Uno de los motivos por lo que se ha apostado por esta línea de investigación, ha sido la mejora del sistema procesal español, ya que es necesarias que se ponga al corriente de los adelantos tecnológicos que la sociedad nos ofrece. Creo que es necesario, que los sistemas judiciales se actualicen, con mecanismos que se encuentran a su alcance, y todo aquello que ayude y los mejore creando un proceso con garantías. Los resultados de la utilización del

${ }^{57}$ VALERO TORRIJOS, J., «El régimen jurídico de la e-Administración: el uso de medios informáticos en el procedimiento administrativo», $2^{\mathrm{a}}$ ed. revisada y ampliada, adaptada a la Ley $11 / 2007$, de acceso electrónico de los ciudadanos a los servicios públicos, Comares, Granada, 2007, pág. 1. 
sistema SmartPerit en los procesos judiciales serían son los siguientes:

i. Al utilizar un sistema automatizado que permite el análisis de un documento manuscrito en el mismo acto del juicio, aporta el elemento de temporalidad, teniendo casi de una forma instantánea la verificación de la prueba. Como la aportación de información que apoye o sirva para contrastar un dictamen pericial ya se ha presentado en la demanda o en la contestación a la demanda, ya están en sede judicial para proceder a su estudio. Al realizar la verificación de la prueba documental por este sistema, estaríamos resolviendo el problema añadido de la ralentización de los procesos por peritajes que se pidan de oficio en algunos casos

ii. Lo más destacable de este sistema, es la fiabilidad que nos ofrece el sistema SmartPerit, arrojando resultados del 99\% de exactitud. Esto, nos da garantías de un proceso más objetivo y justo para ambas partes, ya que se contaría con la certeza del origen de la prueba documental en la causa. Este tipo de fiabilidad, es equiparable a los que utilizan los cuerpos de seguridad del estado en la identificación de personas por medio de la huella dactilar. Es una de las notas más importantes de este tipo de procedimiento, ya que aporta la objetividad que validará la prueba. Este hecho, dará al proceso, unas garantías que no se podrían conseguir, solo con las valoraciones que se conseguirían con los dictámenes de los peritos caligráficos, evitando que un contra peritaje pueda ralentizar el mecanismo de la prueba.

iii. Con la implantación del sistema SmartPerit, nos estaríamos poniendo a la vanguardia en la modernización de las leyes procesales a nivel mundial. A lo largo de mi investigación, no he hallado ningún país que tenga en marcha algún tipo de verificación de este tipo de medios de prueba, en la que se necesita al perito. Aunque en España ya se han iniciado propuestas necesarias con el uso de ciertos avances tecnológicos, mediante la correspondiente modificación legislativa, seríamos pioneros en un sistema innovador y fácilmente realizable.

iv. Esta apuesta se basa en un sistema económico, el cual lo único que necesita para su realización es una tableta, o dispositivo móvil similar, que tengan en su sistema operativo el programa informático. Se propone, que en cada sede judicial se dote de una serie de dispositivos, que el coste medio de los mismos, sería amortizado en su primer mes de uso.

v. La siguiente característica a destacar, es la facilidad para su utilización, ya que no es necesario un conocimiento específico en la materia para proceder a la verificación del documento. Basta con unas simples nociones básicas de informática, que serían 
proporcionadas con un pequeño tutorial que vendría en el propio dispositivo móvil. Por lo tanto, el letrado de la administración de justicia o algún gestor judicial podría utilizarlo sin problemas.

vi. Otras de las ventajas de este sistema, es que es aplicable a cualquier tipo de jurisdicción, ya que la prueba documental suele ser la que más importancia adquiere en la mayoría de los procedimientos. El que exista un mecanismo que sea capaz de facilitar la labor de los peritos, es importante en innumerables procedimientos, en los que básicamente, las únicas pruebas que se aporta son documentales.

vii. Por último, se establece una propuesta de carácter integro, que estaría registrado en cada sede judicial. De esta manera, para posteriores referencias a estas pruebas ya verificadas, se podrán consultar mediante una base de datos que tenga a su disposición la sede judicial.

Se debe tener en cuenta las limitaciones que podemos hallar en nuestro sistema procesal para la utilización de esta herramenta. Es necesario que se efectúe una remodelación en la utilización de los peritos en los procedimientos civiles. A día de hoy, es muy necesaria su intervención en muchas de las causas. Si el programa propuesto se realizara, el papel del perito solo se centraría en la labor dictámenes de valoración de ciertos elementos, como son patrimoniales o bienes muebles, ya que toda la parte de verificación del origen de determinados documentos se vería resuelto por el sistema SmartPerit.

Otras de las limitaciones que tiene que sortear el trabajo propuesto, es la modificación legislativa que necesitaría. Con el panorama político español, es más que complicado que este sistema, sin ningún tipo de referente a nivel mundial, se aplique en España. Se deberá instalar un prototipo piloto en algún juzgado para que sea patente la utilidad del mismo. Los agentes judiciales que estén en el uso de este sistema piloto, serán los que den testimonio de la utilidad y facilidad de uso del mismo. Debido a la carga de trabajo que se sufre en los juzgados españoles, sería un trabajo añadido a estos funcionarios, debiendo dotar de algún agente judicial para facilitar esta labor.

Aunque el impacto económico no sea muy elevado, esto debe estar reflejado en los presupuestos generales del estado, para que se cree una dotación económica para el mantenimiento y compra de estos dispositivos.

Por lo tanto, después de estudiar el sistema procesal en su conjunto, creo que es una apuesta segura, invertir en sistemas como "SmartPerit", donde no solo se va a facilitar las funciones 
del juez, sino que además va a garantizar derechos fundamentales incardinados en nuestra constitución española. El impacto que generará, pondrá al sistema procesal español a la vanguardia a nivel mundial del uso de los avances tecnológicos en los sistemas judiciales, haciendo procesos más efectivos, seguros y justos de nuestra sociedad.

\title{
FROM THE DOCUMENTARY TEST IN ROME TO THE GRAFOTECNIA OF THE XXI CENTURY: THE OBJECTIVATION OF THE DOCUMENTARY TEST IN THE SPANISH JUDICIAL PROCESS
}

\begin{abstract}
The present paper is based in a first moment in the study and distinction between the means of proof from its beginnings in the Roman epoch until the present time, its regulation in different countries of the European Union and the advances in implantation of the technological advances in these countries

In addition, It will provide new features in the field of documentary evidence not contemplated or collected in our order. As a novelty, it will be proposed in the same act of the trial, and using technology, the verification of the documentary evidence, especially focusing on those that were previously of nuclear importance the attendance of calligraphic expert
\end{abstract}

Keywords: Documentary proof, objectification, Roman law, evolution and process.

BIBLIOGRAFIA

ABEL LLUCH, X. Magistrado. Doctor en Derecho. Artículo: "Valoración de los medios de prueba en el proceso civil".2006, p. 311

ARAGONESES MARTÍNEZ, S., HINOJOSA SEGOVIA, R. "Cien cuestiones controvertidas sobre la prueba en el proceso civil', Colex, Barcelona, 2000

ARMENTA DEU, T. "Lecciones de derecho procesal civil”, Marcial Pons, Madrid, 2013, p. vol.12,nº.04,Riode Janeiro,2019.pp.154-188 184 
171.

BALBUENA BALMACEDA, J., "Firmas auténticas y detección de firmas falsas". Editorial Textes \& Prétextes, 2003. p. 67

CAPILlA CASCO, A. y SÁNCHEZ-LOZANO VELASCO, J. en "Patologías de la Audiencia Previa” (I). Economist \& Iuris $\mathrm{N}^{\circ} 185$. Noviembre p.13

CREMADES GARCÍA, V. - ALACID BAÑO, L. M., "Lexnet: el reto de las Nuevas Tecnologías en la administración de justicia”, Revista de la Facultad de Ciencias Sociales y Jurídicas de la Universidad Miguel Hernández, núm. 2, 2007, pp. 46-49

CORTÉS DOMÍNGUEZ, V., y MORENO CATENA, V. "Introducción al Derecho Procesal”, Tirant lo Blanc, Valencia, 2017.

DE ANTÓN y BARBERÁ, F., MÉNDEZ BAQUERO, F., “Análisis de textos manuscritos, firmas y alteraciones documentales", Ed. Tirant lo blanch. 2005

DE PALADELLA SALORD, C., "El documento electrónico como prueba. La reforma del Código Civil Francés”, Revista Electrónica de Derecho Informático, n. ${ }^{\circ}$ 26, septiembre 2000, versión generada por vLex p. 6.

DÍAZ REVORIO, F. J. (2008): “La constitución ante los avances cientificos y tecnológicos: breves reflexiones al hilo de los recientes desarrollos en materia genética y en tecnologías de la información y la comunicación”, Revista de Derecho Político de la UNED, n 71-72.

ESPARZA LEIBAR, I., (2000). “El dictamen de peritos en la Ley 1/2000, de Enjuiciamiento Civil”. Valencia: Tirant lo Blanch

ESCALADA LÓPEZ, Ma L. "El dictamen de peritos en la LEC: Aspectos generales. Especial atención a su naturaleza jurídica", en Revista de Derecho Procesal, 2007, p. 311.

FAUNDEZ-ZANUY, M., ELIOZONDO, D., A., FERRER-BALLESTER, M., A.,y TRAVIESO-GONZALÉZ, C., M., «Authentication of individuals using hand geometry biometrics: A neural network approach», Neural Processing Letters, 26 (2007), 201-16 https://doi.org/10.1007/s11063-007-9052 
FONT SERRA, E., "El dictamen de peritos en la nueva Ley de Enjuiciamiento Civil", en Aportaciones del Profesor Eduardo Font a la doctrina jurídica, Madrid, 2004, p. 139.

GALlAGHER, T.: “UK Citizens' Online Democracy: A case Study”, University of Oxford, 1997 www.aikens.org

GASC, F. \& P. “Reflexiones del código procesal civil francés”. Francia, 2005.

GRAFOPEC, Pericia Caligráfica-Documentoscopia. Asociación nacional de expertos en Grafística y Documentoscopia, Delegación en Navarra. Actualización:07/12/2010http://www.grafopec.com/servicios/pericia-caligrafica documentoscopia/

GONZÁLEZ PILLADO, E., (2000). "La prueba pericial en la nueva Ley de Enjuiciamiento Civil", Revista Xurídica Galega, n² 27, 2000, pp. 307-344.

HERNÁNDEZ GUERRERO / ÁLVAREZ DE LOS RÍOS, (1999) "Medios informáticos y proceso penal”, Estudios Jurídicos. Ministerio Fiscal, 1999-IV, p. 497.

HUGUET TOUS, P. L., "Pistoletazo de salida para la presentación telemática de escritos en los órganos judiciales: el Consejo de Ministros aprueba el Real Decreto que regula la utilización del Sistema LEXNET", La Ley: Revista jurídica española de doctrina, jurisprudencia y bibliografía, núm. 4, 2007, pp. 1446-1448

ILLESCAS RUS, Á., V., “Algunas cuestiones sobre arbitraje en la doctrina de las Audiencias Provinciales", Revista vasca de derecho procesal y arbitraje = Zuzenbide prozesala ta arbitraia euskal aldizkaria, ISSN 0214-7246, Vol. 24, N. 2, 2012, pp. 263-338

LLANEZA GONZÁLEZ, P., "La firma electrónica”, en Iuris-actualidad y prácticas del Derecho, $n^{\circ} 38$, abril 2000, p. 47

M., A., DUARTE. Documentología II. Licenciatura en Criminalística, Cátedra. Technical Report. 2010 p. 34 
MARTÍNEZ NADAL, A., "La ley de firma electrónica”, Civitas, Madrid, 2000.

MARTÍNEZ NADAL, A., "Comentarios sobre la regulación de la firma electrónica”, en Partida Doble n 106, diciembre 1999, p. 19

MAGRO SERVET, V., "La comunicación entre Abogados y Procuradores con los órganos judiciales por medios de las nuevas tecnologías de la información y la comunicación”, Diario La Ley Núm. 5966, 2004, p. 1514.

MONTERO AROCA, J. "La prueba en el proceso civil”, Thomson-Civitas, Navarra, 2007, p. 226

ROSENBERG, SCHWAB y GOTTWALD. 2011: “Zivilprozeßrecht”. München, 645.

SANTANA RAMIREZ, O., "Identificador Off-line de Escritura Manuscrita empleando Técnicas Periciales Caligráficas". Proyecto final de carrera, Universidad de Las Palmas de G.C. 2008.

SANTANA O, TRAVIESO C., M., FERRER MIGUEL A, ALONSO J., “Writer identification based on graphology techniques”. IEEE Aerosp Electron Syst Mag 25, 2010, pp.35-42

SERRA DOMÍNGUEZ, M., "La prueba documental", en "Instituciones del Nuevo Proceso Civil. Comentarios sistemáticos a la Ley 1/2000”, Alonso-Cuevillas Sayrol, J., Barcelona, 2000, p. 256

ORDOÑO ARTÉS, C., "La prueba de reconocimiento judicial en el proceso civil español", Madrid, 1987, p., 171

ORMAZABAL SÁNCHEZ, G., "La prueba documental y los medios e instrumentos idóneos para reproducir imágenes o sonidos o archivar y conocer datos", Madrid, 2000, p. 179

ORTELLS RAMOS, M. "Formas del procedimiento y garantias fundamentales del proceso civil”. Disponible en: http://www.scielo.cl/pdf/iusetp/v16n1/art13.pdf 
PÉREZ GIL, J. (2010). "El conocimiento científico en el Proceso Civil: Ciencia y Tecnología en tela de juicio". Valencia: Tirant Lo Blanch.

PÉREZ RAGONE, A., Y PALOMO VELEZ, D., “Oralidad y prueba: comparación y análisis crítico de las experiencias reformadoras del proceso civil en Alemania y España”. Revista de Derecho de la Pontificia Universidad Católica de Valparaíso XXXII Valparaíso, Chile, 1er Semestre de 2009, pp. 363-406

PICO Y JUNOY, J. "El derecho constitucional a la prueba y su configuración en el nuevo proceso civil español" Disponible en: http://biblio.juridicas.unam.mx/libros/6/2554/31.pdf. p. $\underline{548 .}$

POZO MOREIRA, F. J., "La presentación de demandas y documentos y la realización y notificaciones en los Juzgados y Tribunales del Orden social por medios telemáticos: la reforma del Procedimiento civil y Laboral por la Ley 41/2007”, Diario La Ley, núm. 6890, 2008.

TARUFFO, M., “La prueba”, Marcial Pons, Madrid, 2008, p. 329

TEMPRANO VÁZQUEZ C, "El valor probatorio de los documentos privados y los motivos de impugnación”. Diario de la ley. p. 2, 4 de septiembre de 2015. Abogada. Asociada Senior.

VALERO TORRIJOS, J., "El régimen jurídico de la e-Administración: el uso de medios informáticos en el procedimiento administrativo", $2^{\mathrm{a}}$ ed. revisada y ampliada, adaptada a la Ley 11/2007, de acceso electrónico de los ciudadanos a los servicios públicos, Granada, 2007, p. 1.

Trabalho enviado em 14 de junho de 2019

Aceito em 06 de fevereiro de 2020 